\title{
No association between early antiretroviral therapy during pregnancy and plasma levels of angiogenic factors: a cohort study
}

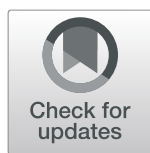

Ameyo Djeha ${ }^{1,2}$, Sylvie Girard ${ }^{1,3}$, Helen Trottier 2,3, Fatima Kakkar ${ }^{4,5,6}$, Hugo Soudeyns ${ }^{6,7,8}$, Marc Boucher ${ }^{1,4,9}$, Normand Lapointe ${ }^{4,6}$ and Isabelle Boucoiran ${ }^{1,2,3,4,9^{*}}$ (D)

\begin{abstract}
Background: Early antiretroviral therapy (ART) during pregnancy has dramatically reduced the risk of perinatal HIV transmission. However, studies have shown an association between premature delivery and the use of ART during pregnancy (particularly protease inhibitor (PI)-based therapies), which could be explained by placental dysfunction. The objective of this study was to evaluate the association of ART (class, duration of exposure and time of initiation) with placental function by using angiogenic factors placental growth factor (PIGF) and soluble fms-like tyrosine kinase-1 (sFlt-1) as biomarkers.

Methods: Clinical and biological data from 159 pregnant women living with HIV were analyzed. Levels of each biomarker were measured in the first and second trimester of pregnancy. After logarithmic transformation, we compared these using generalized estimating equations according to (a) the type of ART; (b) the duration of exposure to ART; and (c) the time of initiation of ART.

Results: After adjusting for variables such as ethnicity, maternal age, gestational age, body mass index, parity, smoking status, and sex of the fetus, we found no significant association between the class of ART (PI-based or not) and serum concentrations of PIGF or sFlt-1. Furthermore, no significant association was found between biomarker levels and the duration of ART exposure or the timing of ART initiation (pre- or post-conception).

Conclusions: This study suggests that first and second trimester angiogenic factor levels are not significantly associated with ART, regardless of the duration or type (with or without PI). These observations seem reassuring when considering the use of ART during early pregnancy.
\end{abstract}

Keywords: Antiretroviral therapy, HIV, Placental function, Placental growth factor, Soluble fms-like tyrosine kinase-1

\section{Background}

An estimated 17.8 million of the 36.7 million people living with HIV in 2016 (48.5\%) were women of childbearing age (15 years and older) [1]. Despite their HIV status, many of these women want to have children [2]. Antiretroviral therapy (ART) reduces the risk of HIV transmission from mother to child to $1-2 \%$, compared to $15-40 \%$ without intervention [3]. ART also improves the health status of the mothers, raises their quality of

\footnotetext{
* Correspondence: isabelle.boucoiran@umontreal.ca

${ }^{1}$ Department of Obstetrics and Gynecology, Faculty of Medicine, Université de Montréal, Montreal, Canada

${ }^{2}$ Department of Social and Preventive Medicine, Faculty of Medicine,

Université de Montréal, Montreal, Canada

Full list of author information is available at the end of the article
}

life and prolongs their life expectancy, leading more and more women living with HIV to conceive [2]. According to current recommendations, all adults living with HIV should be treated with ART [4-7]. As a result, most women living with HIV are now already on ART at the time of conception and early pregnancy, whereas in the past, ART was initiated only in the second trimester of pregnancy [8].

Although ART has significantly reduced rates of adverse perinatal outcomes such as stillbirth, intrauterine growth restriction and preterm birth associated with maternal HIV infection $[9,10]$, these rates are still higher for women living with HIV while receiving ART compared to HIV-negative women [11-14]. These adverse

(c) The Author(s). 2019 Open Access This article is distributed under the terms of the Creative Commons Attribution 4.0 International License (http://creativecommons.org/licenses/by/4.0/), which permits unrestricted use, distribution, and reproduction in any medium, provided you give appropriate credit to the original author(s) and the source, provide a link to the Creative Commons license, and indicate if changes were made. The Creative Commons Public Domain Dedication waiver (http://creativecommons.org/publicdomain/zero/1.0/) applies to the data made available in this article, unless otherwise stated. 
pregnancy outcomes may be related to the class of ART used during pregnancy, notably to protease inhibitor (PI) regimens [14-18], which have been associated with placental vascular changes [19].

Anti-angiogenic effects have been reported following the use of PIs in oncology [20,21]. Placental growth factor (PlGF) and the soluble receptor, soluble fms-like tyrosine kinase-1 (sFlt-1) are respectively pro- and antiangiogenic factors. PIGF is synthesized in several organs (heart, skeletal muscle, lungs, adipose tissue, platelets). sFlt- 1 is released by vascular endothelial cells and circulating cells (monocytes, macrophages, platelets). The placenta (trophoblast and endothelial cells of the placental villi) is the main source of PIGF and sFlt-1 during pregnancy; they participate in vasculogenesis and fetoplacental angiogenesis. Increased sFlt-1 and decreased free PIGF levels in maternal blood, or increased sFlt-1/ PIGF ratio are directly implicated in the pathophysiology of preeclampsia, including maternal endothelial dysfunction [22-29]. A change in these factors is also associated with other complications during pregnancy, such as intrauterine growth restriction [27, 30], preterm delivery [31], spontaneous abortion and stillbirth [26, 32, 33], ,confirming the association between impaired placental perfusion and systemic changes in angiogenic factors [34-36]. These observations have been noted in cohorts of women living with HIV [37].

We hypothesized that pregnant women living with HIV who receive PI-based ART may have impaired placental function compared to untreated women living with HIV, altering the plasma concentration of the angiogenic factors placental growth factor (PIGF) and soluble fms-like tyrosine kinase-1 (sFlt-1). These disturbances could be influenced by the duration of ART exposure or by the timing of ART initiation. The objective of this study was to evaluate the association of the class, duration and timing of initiation of ART with serum concentrations of PIGF and sFlt-1 biomarkers, in the first and second trimesters of pregnancy.

\section{Methods}

This study used data from the database of pregnant women living with HIV who were consented and enrolled at their first antenatal visit in the prospective cohort of Centre maternel et infantile sur le sida (CMIS), CHU Sainte-Justine, Montreal, QC, Canada. The CMIS database and biobank contain information and biologic samples from more than 900 mother-child pairs and enrolls approximately 40 additional pairs annually. Deidentified data are collected and managed using REDCap electronic data capture tools [38].

This study included data from pregnant women who were enrolled between January 2003 and December 2016, and for whom serum samples were available during both the first trimester (5-14 weeks) and the second trimester (15-28 weeks) of pregnancy. Maternal serum samples were collected at the time of clinically indicated blood tests and stored at $-80^{\circ} \mathrm{C}$ for research purpose. Levels of PlGF and sFlt-1 were measured using DuoSet Enzyme-Linked Immunosorbent Assay (ELISA) kits (R\&D systems, Minneapolis, MN). Lower limits of detection were $15.6 \mathrm{pg} / \mathrm{ml}$ (sFlt-1) and $62.5 \mathrm{pg} / \mathrm{ml}$ (PlGF). There was no dilution for PIGF and it is a factor of 5 for sFLT-1. In all cases, both biomarkers were assayed using the same serum aliquot.

Gestational age was defined based on the crown-rump length from the first-trimester ultrasound if available and if not, from the date of the last menstrual period. Preterm birth was defined as delivery before 37 weeks of gestation. Small for gestational age (SGA) was defined as a birth weight below the 10th percentile for the gestational age.

Women living with HIV were categorized according to ART exposure at first and second trimester (PI-based ART, other ART, or no treatment). The duration of ART exposure during pregnancy was expressed in weeks since conception. Time of initiation of ART was defined relative to conception (either before conception or during pregnancy).

\section{Statistical analysis}

Descriptive analyses were conducted on the sociodemographic, clinical and biological data of the participants. For each categorical and continuous variable, data are reported as proportions or mean (with standard deviation) or median with interquartile range (IQR) respectively. The Wilcoxon test for matched samples was used to compare serum marker concentrations in the first and second trimesters and Mann-Withney $U$ test to compare angiogenic factor levels in the two groups with undetectable viral load or not.

Linear regression evaluated the association between angiogenic factor concentrations and birth outcome groups (preterm birth and SGA) at the first and second trimester. To account for repeated measurements from the same individuals in the first and second trimesters of pregnancy, linear generalized estimating equations (GEE) were used to analyze the association between ART (class, duration of exposure and initiation time) and plasma concentration of the two biomarkers. A first-order autoregressive (AR1) correlation matrix was used. Models were adjusted for potential confounding factors previously identified in a review of the literature, including ethnicity, parity, maternal age, gestational age, body mass index (BMI), smoking status and sex of the fetus [39-43]. Confounding variables that resulted in a $+/-10 \%$ variation of the regression coefficient when introduced into the bivariate model were retained in the 
final model. All variables with a $p<0.05$ were also included in the final model. As suggested by residual analysis, a logarithmic transformation of biomarkers levels was performed. Using sensitivity analyses, we considered models with different unstructured or exchangeable correlation matrices and compared these models using Quasi-likelihood under Independence Model Criterion (QIC). A value of $p<0.05$ was considered statistically significant. $95 \%$ confidence intervals are shown. Considering the values of PlGF and sFlt1 (mean and standard deviation) obtained in the reference group (group without ART), we calculated that with the available sample size $(n=159)$, we could have been able to detect respective mean (delta) differences of 33.67 and
$1905.15 \mathrm{pg} / \mathrm{ml}$ using an alpha error of 0.05 and a statistical power (beta) of $80 \%$. Statistical analyses were performed using IBM SPSS Statistics for Windows version 24 (IBM Corp, Armonk, NY).

The use of the CMIS database and biobank for this study was approved by the directors of the CMIS (FK and NL) and CHU Sainte-Justine ethics review board. All participants provided written informed consent.

\section{Results}

A total of 318 paired serum samples from 159 pregnant women living with HIV were analyzed. Demographic,

Table 1 Population characteristics

\begin{tabular}{|c|c|c|c|c|c|c|c|}
\hline \multirow[t]{2}{*}{ Characteristics } & \multicolumn{3}{|c|}{ 1st trimester $n=159$} & \multicolumn{3}{|c|}{ 2nd trimester $n=159$} & \multirow{2}{*}{$\begin{array}{l}\text { Total } \\
n=159\end{array}$} \\
\hline & No ART $n=50$ & $\begin{array}{l}\mathrm{Pl} \\
n=89\end{array}$ & $\begin{array}{l}\text { Other regimens } \\
n=20\end{array}$ & $\begin{array}{l}\text { No ART } \\
n=6\end{array}$ & $\begin{array}{l}\mathrm{PI} \\
n=131\end{array}$ & $\begin{array}{l}\text { Other regimens } \\
n=22\end{array}$ & \\
\hline $\begin{array}{l}\text { Maternal age at } \\
\text { delivery, years, mean } \pm S D\end{array}$ & $31.7 \pm 5.3$ & $33.1 \pm 4.9$ & $31.3 \pm 5.0$ & $29.7 \pm 3.0$ & $32.5 \pm 5.1$ & $32.3 \pm 5.4$ & $32.4 \pm 5.1$ \\
\hline \multicolumn{8}{|l|}{ Ethnicity, n (\%) } \\
\hline Afro-Caribbean & $43(86.0)$ & $69(77.5)$ & $18(90.0)$ & $6(100.0)$ & 103 (78.6) & $21(95.5)$ & $130(81.8)$ \\
\hline Caucasian & $7(14.0)$ & $17(19.1)$ & $1(5.0)$ & $0(0.0)$ & $24(18.3)$ & $1(4.5)$ & $25(15.7)$ \\
\hline Other & $0(0.0)$ & $3(3.4)$ & $1(5.0)$ & $0(0.0)$ & $0(0.0)$ & $0(0.0)$ & $4(2.5)$ \\
\hline $\begin{array}{l}\mathrm{BMI}, \mathrm{kg} / \mathrm{m}^{2} \\
\text { median }[\mathrm{IQR}]\end{array}$ & 27.2 [24.9-31.0] & 25.8 [22.8-29.9] & 26.5 [22.9-30.3] & 28.2 [24.4-34.9] & $26.4[23.6-30.4]$ & 24.9 [23.2-28.7] & $\begin{array}{l}26.3 \\
{[23.5-30.2]}\end{array}$ \\
\hline \multicolumn{8}{|l|}{ Parity, n (\%) } \\
\hline 0 & $15(30.0)$ & $31(34.8)$ & $6(30.0)$ & $2(33.3)$ & $41(31.3)$ & $9(40.9)$ & $52(32.7)$ \\
\hline 1 & $18(36.0)$ & $31(34.8)$ & $10(50.0)$ & $4(66.7)$ & $45(34.4)$ & $10(45.5)$ & $59(37.1)$ \\
\hline 2 & $12(24.0)$ & $14(15.7)$ & $1(5.0)$ & $0(0.0)$ & $26(19.8)$ & $1(4.5)$ & $27(17.0)$ \\
\hline 3 and more & $5(10)$ & $13(14.7)$ & $3(15.0)$ & $0(0.0)$ & $19(14.5)$ & $2(9.1)$ & $21(13.2)$ \\
\hline Smoker, n (\%) & $6(12.0)$ & $8(9.0)$ & $1(5.0)$ & $0(0.0)$ & $6(4.6)$ & $0(0.0)$ & \\
\hline $\begin{array}{l}\text { Chronic hypertension, } \\
\text { n (\%) }\end{array}$ & $2(4.0)$ & $1(1.1)$ & $0(0.0)$ & $0(0.0)$ & $3(2.3)$ & $0(0.0)$ & $3(1.9)$ \\
\hline $\begin{array}{l}\text { Gestational hypertension } \\
\text { or preeclampsia, n (\%) }\end{array}$ & $4(8.0)$ & $9(10.1)$ & $2(10.0)$ & $1(16.7)$ & $11(7.2)$ & $3(13.6)$ & $15(9.4)$ \\
\hline \multicolumn{8}{|l|}{ Sex of fetus, n (\%) } \\
\hline Male & $25(50.0)$ & $53(59.6)$ & $4(20.0)$ & $1(16.7)$ & $76(58.0)$ & $5(22.7)$ & $82(51.6)$ \\
\hline \multicolumn{8}{|l|}{ 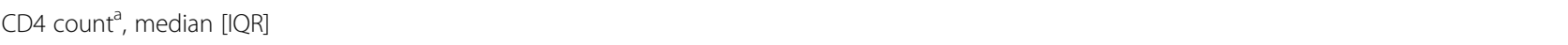 } \\
\hline Total $/ \mathrm{mm}^{3}$ & $\begin{array}{l}495.5 \\
{[270.0-679.5]}\end{array}$ & $\begin{array}{l}573.5 \\
{[404.25-751.5]}\end{array}$ & $\begin{array}{l}580.5 \\
{[372.5-733.5]}\end{array}$ & $\begin{array}{l}493.5 \\
{[193.5-859.5]}\end{array}$ & $\begin{array}{l}561.0 \\
{[378.5-722.5]}\end{array}$ & $\begin{array}{l}645.0 \\
{[470.75-1056.0]}\end{array}$ & \\
\hline Percentage & $\begin{array}{l}25.0 \\
{[16.0-33.0]}\end{array}$ & $\begin{array}{l}32.0 \\
{[25.0-38.5]}\end{array}$ & $\begin{array}{l}33.5 \\
{[23.0-43.5]}\end{array}$ & $\begin{array}{l}26.0 \\
{[17.0-37.0]}\end{array}$ & $\begin{array}{l}31.0 \\
{[24.0-39.0]}\end{array}$ & $\begin{array}{l}40.0 \\
{[27.0-44.0]}\end{array}$ & \\
\hline Undetectable viral load ${ }^{\mathrm{a}}, \mathrm{n}(\%)$ & $4(8.0)$ & $72(80.9)$ & $16(80.0)$ & $2(33.3)$ & $94(71.8)$ & 19 (86.4) & \\
\hline \multicolumn{8}{|l|}{ Pregnancy outcome, n (\%) } \\
\hline SGA & $8(16.0)$ & $19(21.3)$ & $2(10.0)$ & $1(16.7)$ & $26(19.8)$ & $2(9.1)$ & 29 (18.6) \\
\hline Preterm birth & $6(12.0)$ & $17(19.1)$ & $2(10.0)$ & $0(0.0)$ & $22(16.8)$ & $3(13.6)$ & $25(15.7)$ \\
\hline $\begin{array}{l}\text { Gestationnal age } \\
\text { weeks, median }[\mathrm{IQR}]\end{array}$ & $9.7[7.9-11.9]$ & $10.7[8.9-11.9]$ & $10.7[7.9-11.8]$ & $18.3[15.8-19.1]$ & $19.6[17.1-21.3]$ & 19.3 [17.1-23.0] & \\
\hline
\end{tabular}


clinical and biological characteristics of the participants are presented in Table 1 . In the first trimester, nearly $69 \%$ of women were receiving ART, $82 \%$ of whom were receiving PI-based regimens. In the second trimester, more than $96 \%$ were receiving ART, $86 \%$ of which were PI-based. The mean duration of ART exposure from the start of pregnancy to first-trimester and second-trimester biomarker testing was $9.5 \pm 2.9$ weeks and $14.8 \pm 7.1$ weeks, respectively. a)

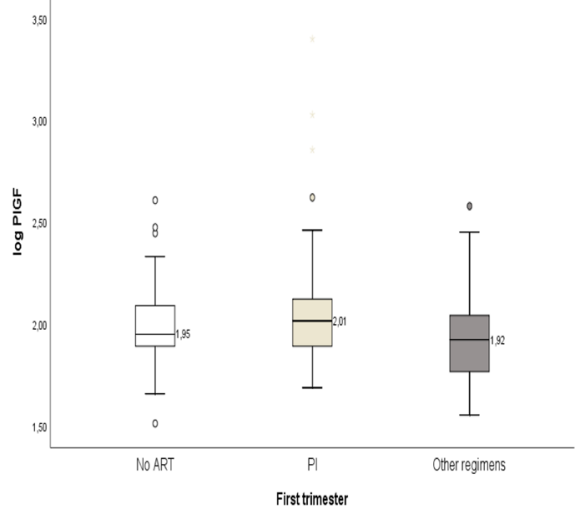

c)

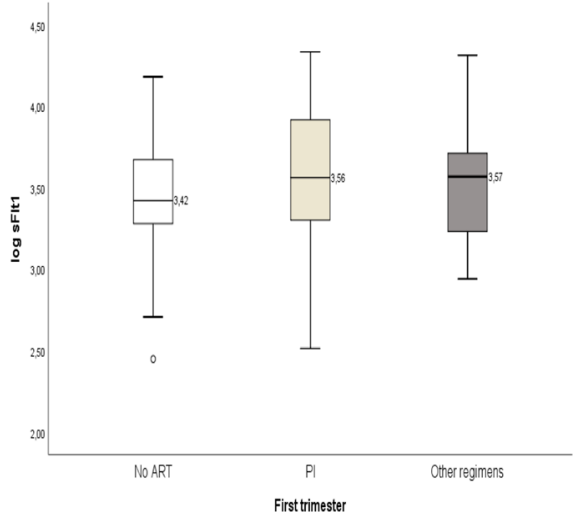

e)

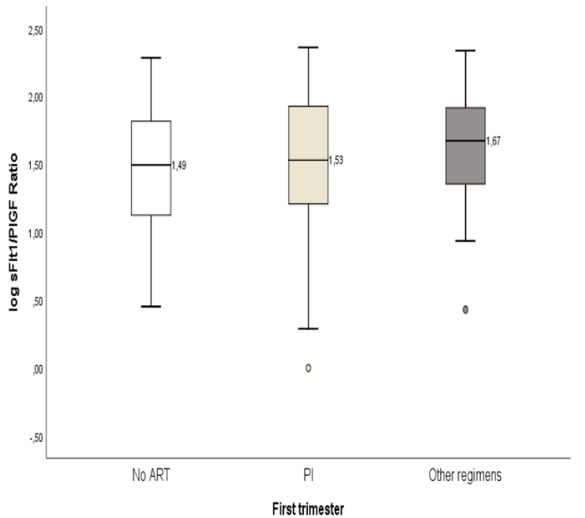

b)

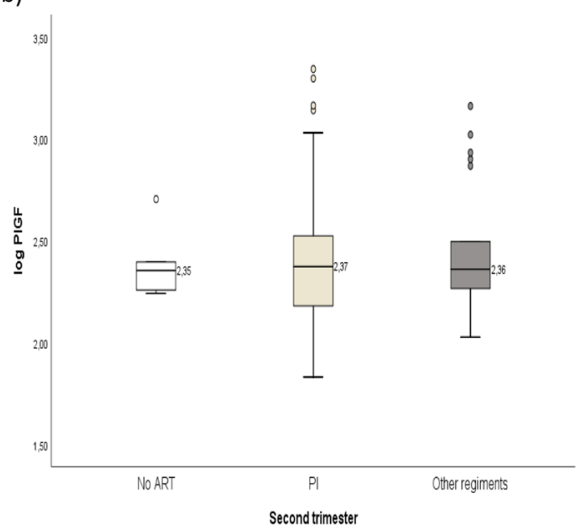

d)

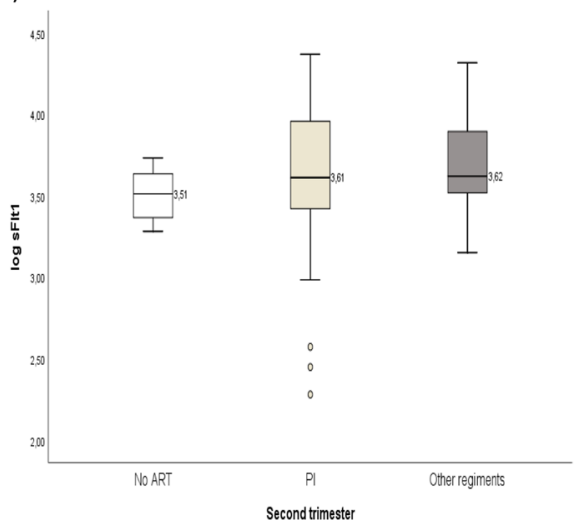

f)

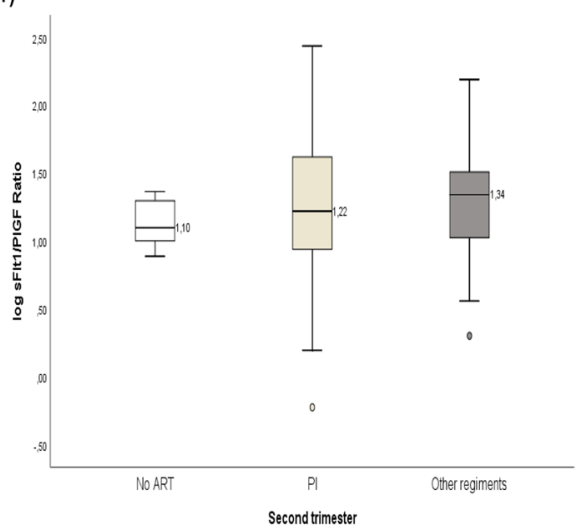

Fig. 1 Biomarker distribution by class of antiretroviral therapy (Box-and-whiskers representation). a Placental growth factor level (PIGF) in 1st trimester; b PIGF level in 2nd trimester; c soluble fms-like tyrosine kinase-1 (sFlt-1) level in 1st trimester; $\mathbf{d}$ sFlt-1 level in 2nd trimester e sFlt-1/PIGF

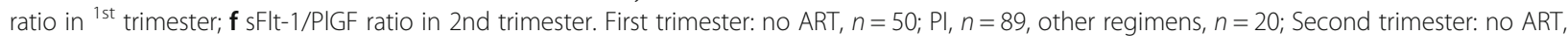
$n=6 ; \mathrm{Pl}, n=131$, other regimens, $n=22$. The boxes extend from the 25 th percentile to the 75 th percentile (i.e., the interquartile range); lines inside boxes represent median values. Lines emerging from boxes (i.e., the whiskers) extend to the upper and lower adjacent values. The lower adjacent values provide an estimate of the lower limit of the array and represents the first quartile value less 1.5 times the difference between the first and third quartiles. The upper adjacent value provides an estimate of the upper limit of the array and represents the third quartile value plus 1.5 times the difference between the first and third quartiles. Values outside these limits are outliers. ART: antiretroviral therapy; PI: protease inhibitor 


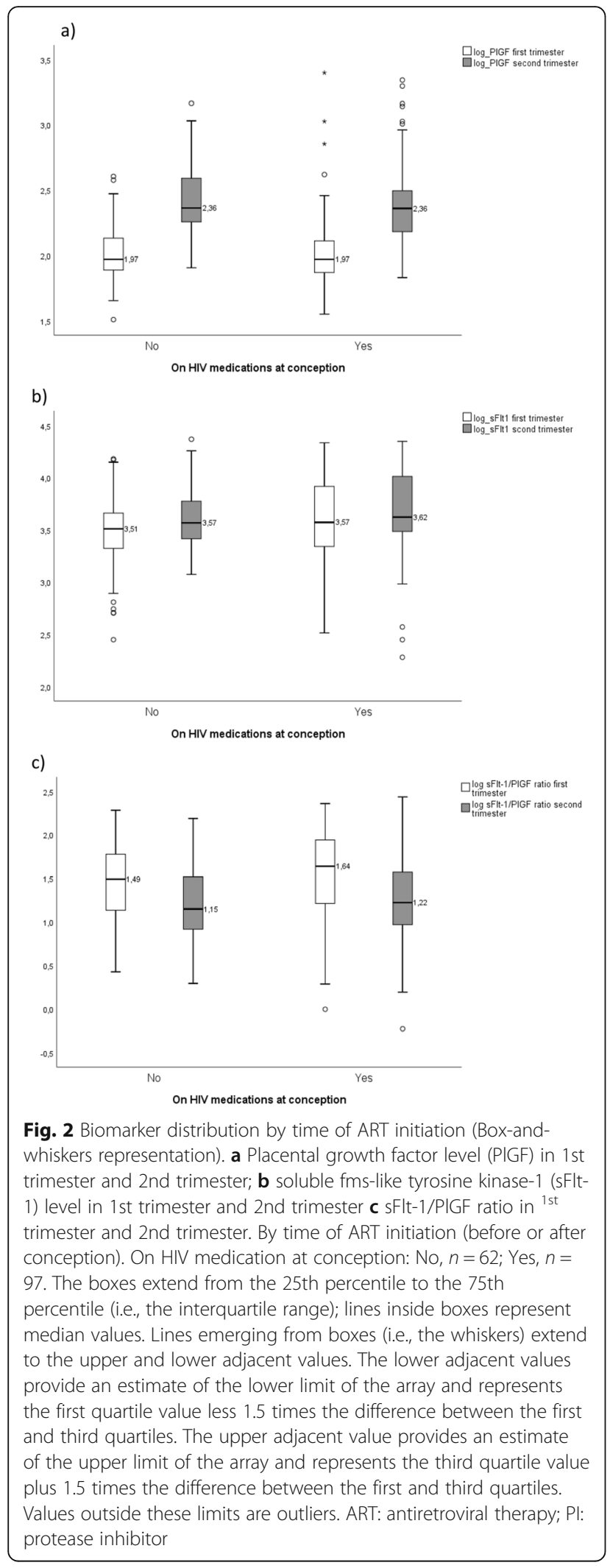

The median concentration of PlGF in the first trimester was $93.5 \mathrm{pg} / \mathrm{ml} \quad[\mathrm{IQR}=74.2-129.0]$ compared to $229.0 \mathrm{pg} / \mathrm{ml}[\mathrm{IQR}=154.8-329.0]$ in the 2 nd trimester $(p<0.0001)$. The median concentration of sFlt-1 in the first trimester was $3372.7 \mathrm{pg} / \mathrm{ml}$ [IQR $=1736.7-5781.8]$ compared to $4009.1 \mathrm{pg} / \mathrm{ml}[\mathrm{IQR}=2600.0-8236.4]$ in the second trimester $(p=0.006)$. The angiogenic factors levels are similar in the two groups with undetectable viral load or not in the first trimester (respectively 93.5 $\mathrm{pg} / \mathrm{ml} \quad[\mathrm{IQR}=74.2-125.0] \quad$ compared to $91.9 \mathrm{pg} / \mathrm{ml}$ $[\mathrm{IQR}=77.4-145.2] ; p=0.752$ for PlGF and $3668.2 \mathrm{pg} / \mathrm{ml}$ $[\mathrm{IQR}=1452.3-7509.1]$ compared to $2850.0 \mathrm{pg} / \mathrm{ml}[\mathrm{IQR}=$ 1963.6-5554.5]; $p=0.194$ for sFlt-1) and in the second trimester (respectively $229.0 \mathrm{pg} / \mathrm{ml}[\mathrm{IQR}=148.4-322.6]$ compared to $240.3 \mathrm{pg} / \mathrm{ml}[\mathrm{IQR}=177.4-392.7] ; p=0.328$ for PlGF and $4145.5 \mathrm{pg} / \mathrm{ml} \quad[\mathrm{IQR}=2600.0-10,190.9]$ compared to $3918.2 \mathrm{pg} / \mathrm{ml} \quad[\mathrm{IQR}=2611.4-6725.0] ; p=$ 0.659 for sFlt-1).

Figure 1 shows the distribution of the different biomarkers according to the class of ART and Fig. 2 the distribution by time of ART initiation.

Bivariate comparisons are presented in Table 2 . After adjustment, no significant association was found between the class of ART (whether PI-based or not) and the level of PlGF, sFlt-1 or the PlGF/SFlt-1 ratio (Table 2). Furthermore, no significant association was found between serum angiogenic factors and duration of ART exposure (including all PI-containing ART) or initiation time (pre-conception versus during pregnancy) (Table 2).

The association between angiogenic factor concentrations and birth outcomes (preterm birth and SGA) was further evaluated (Table 3). After adjustment, significantly lower concentrations of sFlt- 1 and sFlt/PIGF ratio at the first trimester and significantly lower concentrations of PlGF at the second trimester were seen in SGA cases than in normal weight cases. No significant association between angiogenic factor concentration and preterm birth was observed.

\section{Discussions}

In this cohort study, first and second trimester angiogenic factor concentrations are not significantly associated with ART exposure of any type and duration, nor are they associated with the timing of treatment initiation (pre-conception or during pregnancy). The biomarker levels observed among women living with HIV appear to be similar to those reported in HIV-negative women in other studies [44-48]. The strong association of these angiogenic factor concentrations with gestational age and other baseline data (BMI, ethnicity) is consistent with data from HIV-negative pregnant women $[48,49]$. This explains why the significant differences between ART exposure groups in the unadjusted 
Table 2 Association between biomarkers and ART (type, duration and initiation time)

\begin{tabular}{|c|c|c|c|c|c|c|}
\hline Biomarkers & Crude coefficient & $\mathrm{Cl}(95 \%)$ & $p$-value & Adjusted coefficient $^{a}$ & Adjusted Cl (95\%) & $p$-value \\
\hline \multicolumn{7}{|l|}{ PIGF } \\
\hline Pl-based ART ${ }^{\mathrm{b}}$ & 0.238 & $0.166-0.310$ & 0.000 & $0.018^{c}$ & $-0.051-0.088$ & 0.611 \\
\hline Other ART ${ }^{\mathrm{b}}$ & 0.201 & $0.095-0.307$ & 0.000 & $0.028^{c}$ & $-0.064-0.121$ & 0.552 \\
\hline ART exposure duration & 0.020 & $0.014-0.026$ & 0.000 & $0.001^{d}$ & $-0.006-0.007$ & 0.873 \\
\hline PI exposure duration & 0.018 & $0.011-0.025$ & 0.000 & $0.000^{d}$ & $-0.007-0.006$ & 0.936 \\
\hline Time of ART initiation ${ }^{e}$ & -0.019 & $-0.089-0.051$ & 0.592 & $0.000^{d}$ & $-0.066-0.066$ & 0.997 \\
\hline \multicolumn{7}{|l|}{ sFlt1 } \\
\hline PI-based ART ${ }^{b}$ & 0.306 & $0.109-0.503$ & 0.002 & $0.177^{f}$ & $-0.032-0.386$ & 0.097 \\
\hline Other $A R T^{b}$ & 0.233 & $-0.108-0.573$ & 0.180 & $0.091^{f}$ & $-0.246-0.428$ & 0.597 \\
\hline ART exposure duration & 0.003 & $-0.008-0.015$ & 0.584 & $-0.001^{9}$ & $-0.014-0.012$ & 0.872 \\
\hline PI exposure duration & 0.007 & $-0.004-0.019$ & 0.218 & $0.002^{9}$ & $-0.010-0.015$ & 0.722 \\
\hline Time of ART initiation $^{e}$ & 0.085 & $-0.074-0.244$ & 0.294 & $0.024^{h}$ & $-0.139-0.188$ & 0.772 \\
\hline \multicolumn{7}{|l|}{ sFlt1/PIGF Ratio } \\
\hline PI-based ART ${ }^{\mathrm{b}}$ & 0.033 & $-0.179-0.245$ & 0.759 & $0.145^{i}$ & $-0.076-0.366$ & 0.199 \\
\hline Other $A R T^{b}$ & -0.036 & $-0.386-0.314$ & 0.840 & $0.063^{i}$ & $-0.319-0.445$ & 0.747 \\
\hline ART exposure duration & -0.014 & $-0.028-0.000$ & 0.044 & $0.000^{f}$ & $-0.018-0.017$ & 0.956 \\
\hline PI exposure duration & -0.007 & $-0.021-0.006$ & 0.299 & $0.003^{h}$ & $-0.013-0.019$ & 0.683 \\
\hline Time of ART initiation ${ }^{e}$ & 0.104 & $-0.071-0.279$ & 0.243 & $0.028^{h}$ & $-0.152-0.208$ & 0.761 \\
\hline
\end{tabular}

ART Antiretroviral therapy, PI Protease inhibitor, Cl Confidence interval

a Linear Generalized Estimating Equations

${ }^{b}$ Control: no ART

c Adjusted for gestational age at the date of test and ethnicity

${ }^{d}$ Adjusted for gestational age at the date of test, body mass index and ethnicity

e Control: ART initiated during pregnancy

${ }^{f}$ Adjusted for gestational age at the date of test and body mass index

${ }^{9}$ Adjusted for gestational age at the date of test and maternal age

${ }^{\mathrm{h}}$ Adjusted for gestational age at the date of test, maternal age and ethnicity

i Adjusted for gestational age at the date of test, maternal age, body mass index, parity, and sex of the fetus

analyses were not confirmed in the multivariate analyses (Table 2). The association between angiogenic factor concentrations and adverse pregnancy outcomes is consistent with reports in HIV-negative women $[27,30]$ and in women living with HIV [37].

The absence of an HIV-negative control group in this study is a limitation that prevents us from assessing the impact of HIV infection itself on angiogenic factors and whether the infection itself can lead to dysregulation of angiogenesis. However, it seems unlikely that viral activity has much of an influence on angiogenic factor concentrations when we consider the similarity of levels in the untreated group (with a detectable viral load) compared to the treated one. The heterogeneity of ART regimens received by women is another limitation of our study (see Additional file 1: Table S1, which illustrates the different nucleoside reverse transcriptase inhibitors in the ART). As drug use was very rare in our cohort (< $1 \%$ ), we could not evaluate the impact of this factor on placental angiogenic factors. However, repeated measurements in the first and second trimester increased the number of observations, giving us a greater statistical power. Measurements of the levels of angiogenic factors were all performed on the same day to minimize interassay variability. We also attempted to eliminate bias with a conservative method of adjustment for potential confounding factors.

Very few studies have explored the relationship between ART and the serum concentration of these angiogenic factors during pregnancy. Studies in oncology, however, have suggested anti-angiogenic effects for some PIs $[20,21]$. The effects of PIs on placental vascular system formation and fetal development have to date only been examined in a mouse model [50]. Mice exposed to ART had significantly smaller fetuses and placentas compared to controls. Litter size and fetal viability were negatively impacted by exposure to two nucleoside analogs and two PIs at doses equivalent to human therapeutic doses. Although PlGF levels were unchanged, significantly lower levels of placental sFlt-1 were noted $[19,50]$.

Lower PlGF levels were reported in South Africa amongst pregnant women living with HIV, compared to uninfected pregnant women, whether or not they were 
Table 3 Association between biomarkers and adverse birth outcomes

\begin{tabular}{|c|c|c|c|c|c|c|}
\hline Biomarkers & Crude coefficient & $\mathrm{Cl}(95 \%)$ & $p$-value & Adjusted coefficient ${ }^{\mathrm{a}}$ & Adjusted Cl (95\%) & $p$-value \\
\hline \multicolumn{7}{|l|}{ First trimester } \\
\hline \multicolumn{7}{|l|}{ PIGF } \\
\hline SGA & -0.006 & $-0.109-0.097$ & 0.904 & $-0.023^{b}$ & $-0.130-0.085$ & 0.980 \\
\hline Preterm birth & 0.054 & $-0.046-0.154$ & 0.290 & $0.056^{c}$ & $-0.043-0.155$ & 0.266 \\
\hline \multicolumn{7}{|l|}{ sFlt1 } \\
\hline SGA & -0.192 & $-0.384-0.001$ & 0.051 & $-0.260^{d}$ & $-0.432--0.088$ & 0.003 \\
\hline Preterm birth & 0.090 & $-0.100-0.280$ & 0.350 & $0.064^{d}$ & $-0.106-0.233$ & 0.458 \\
\hline \multicolumn{7}{|l|}{ sFlt1/PIGF Ratio } \\
\hline SGA & -0.184 & $-0.415-0.048$ & 0.119 & $-0.227^{d}$ & $-0.437--0.016$ & 0.035 \\
\hline Preterm birth & 0.035 & $-0.193-0.264$ & 0.760 & $0.002^{e}$ & $-0.207-0.211$ & 0.986 \\
\hline \multicolumn{7}{|l|}{ Second trimester } \\
\hline \multicolumn{7}{|l|}{ PIGF } \\
\hline SGA & -0.096 & $-0.220-0.028$ & 0.127 & $-0.117^{f}$ & $-0.225--0.010$ & 0.033 \\
\hline Preterm birth & -0.071 & $-0.193-0.050$ & 0.248 & $-0.006^{9}$ & $-0.113-0.100$ & 0.909 \\
\hline \multicolumn{7}{|l|}{ sFlt1 } \\
\hline SGA & 0.007 & $-0.147-0.161$ & 0.930 & $0.048^{h}$ & $-0.121-0.216$ & 0.576 \\
\hline Preterm birth & 0.072 & $-0.082-0.226$ & 0.920 & $-0.077^{i}$ & $-0.083-0.237$ & 0.342 \\
\hline \multicolumn{7}{|l|}{ sFlt1/PIGF Ratio } \\
\hline SGA & 0.107 & $-0.097-0.306$ & 0.291 & $0.162^{j}$ & $-0.038-0.362$ & 0.111 \\
\hline Preterm birth & 0.132 & $-0.067-0.331$ & 0.193 & $0.013^{k}$ & $-0.193-0.218$ & 0.903 \\
\hline
\end{tabular}

ART Antiretroviral therapy, Cl Confidence interval, SGA Small for gestational age

aLinear regression

${ }^{\mathrm{b}}$ Adjusted for gestational age at the date of test, maternal age, body mass index, parity, sex of the fetus and ART

${ }^{c}$ Adjusted for gestational age at the date of test and ART

${ }^{\mathrm{d}}$ Adjusted for gestational age at the date of test, body mass index, sex of the fetus and ART

${ }^{\text {e}}$ Adjusted for gestational age at the date of test, body mass index, ethnicity, parity, sex of the fetus and ART

${ }_{\mathrm{f}}^{\mathrm{A} A j \mathrm{j} u s t e d}$ for gestational age at the date of test, maternal age, body mass index, ethnicity, parity, and ART

${ }^{9}$ Adjusted for gestational age at the date of test, body mass index, ethnicity, parity, and ART

${ }^{h}$ Adjusted for gestational age at the date of test, maternal age, body mass index, ethnicity, parity, smoking, sex of the fetus and ART

'Adjusted for gestational age at the date of test, maternal age, smoking, sex of the fetus and ART

${ }^{\mathrm{j}}$ Adjusted for gestational age at the date of test, maternal age, body mass index, ethnicity, parity, smoking and ART

${ }^{\mathrm{k}}$ Adjusted for gestational age at the date of test, maternal age, body mass index, smoking, sex of the fetus and ART

preeclamptic [51]. However, the sample size in that study was small (27 HIV-negative women and 31 women living with HIV) and the authors did not specify if the subjects were receiving ART. By contrast, Govender et al. reported no relationship between HIV infection and angiogenic factors measured in the third trimester of pregnancy, but provided no details concerning ART exposure [25].

Even though our study is the first to report data on periconceptionnal and first trimester ART exposure, our results are consistent with those of a recent study in Uganda of 326 pregnant women living with HIV who began receiving ART in the second trimester. That study reported no significant difference in the levels of angiogenic factors according to the class of ART (PI vs nonnucleoside reverse transcriptase inhibitor (NNRTI) [37]. Similarly, another study of a cohort of 71 women whose ART was initiated after 26 weeks of pregnancy also found no association between the duration of ART exposure or changes in angiogenic factor concentrations [52]. The authors reported no significant changes in angiogenic marker levels after 1 month of ART, and no significant differences in serum concentration of sFlt-1 or PlGF relating to the type of ART (NNRTI versus PI).

To our knowledge, our study constitutes the first report on first-trimester angiogenic marker levels in a cohort of women who received early exposure to ART during pregnancy. Our results are consistent with reports on later ART initiation in pregnancy [37]. These finding needs to be confirmed by the study of circulating levels of other angiogenic biomarkers as well as direct study of the early placenta vasculature. If confirmed, even though angiogenic processes in the placenta are critical regulators of fetal growth and impact birth outcomes, the pathophysiological mechanism of the association between ART and preterm birth would unlikely be through an early and direct effect on placental angiogenesis. Immune restoration as a result of ART initiation is 
a hypothesis that needs to be explored [53]. Indeed, a study from the United Kingdom suggests that ARTinduced immune reconstitution plays a central role in the pathogenesis of pre-eclampsia in pregnant, women living with HIV receiving ART. HIV infection could be associated with a low risk of preeclampsia and this risk restored to the expected values in women treated with ART [53].

\section{Conclusions}

This study suggests that ART, whether PI-based or not, is not associated with the serum concentration of angiogenic factors PlGF and sFlt-1 in the first and second trimesters of pregnancy. There is also no significant association with duration of treatment or timing of treatment initiation (before conception or during pregnancy). These observations seem generally reassuring for the potential consequences of early ART use during pregnancy. Further studies are needed to confirm the safety of early ART exposure regarding placental angiogenesis and its implications for adverse pregnancy outcomes, especially considering the rapid evolution of ART guidelines.

\section{Supplementary information}

Supplementary information accompanies this paper at https://doi.org/10 1186/s12884-019-2600-4.

Additional file 1. Table that illustrates the different nucleoside reverse transcriptase inhibitors in the ART.

\section{Abbreviations}

ART: Antiretroviral therapy; BMI: Body mass index; CMIS: Centre maternel et infantile sur le sida; ELISA: Enzyme-Linked Immunosorbent Assay; GEE: Generalized estimating equations; IQR: Interquartile range; NNRTI: Nonnucleoside reverse transcriptase inhibitor; PI: Protease inhibitor; PIGF: Placental growth factor; sFlt-1: Soluble fms-like tyrosine kinase-1; SGA: Small for gestational age

\section{Acknowledgements}

The authors wish to thank the CMIS staff and Mrs. Martine Caty (Unité d'immunopathologie virale, Centre de recherche du CHU Sainte-Justine, Montreal, Canada) for excellent technical assistance, and all the women in the CMIS cohort for their contribution to the success of this project. We would like to extend our appreciation to John Davison for the translation.

\section{Authors' contributions}

$\mathrm{AD}$ performed the quantitative analysis of the data and was a major contributor in writing the manuscript. SG performed the PIGF and Sflt1 measurements and provided expertise on placental inflammation in the interpretation of results. HT contributed to the development of methods and the statistical analysis of data. IB designed the research protocol, supervised the analysis and interpretation of the results. MB directed the recruitment of the participants. HS is responsible for the management of the CMIS biobank. FK and NL provided access to the CMIS database. All co-authors provided suggestions and comments throughout the project, reviewed the manuscript and approved the final version.

\section{Funding}

This study was funded by an infrastructure grant from Réseau sida et maladies infectieuses (SIDA/MI) of the Fonds de recherche du Québec - Santé
(FRQ-S) to IB and HS. The funding sources were not involved in the conduct of this study.

\section{Availability of data and materials}

The datasets generated and/or analysed during the current study are not publicly available due to restrictions associated with anonymity of participants but are available from the corresponding author on reasonable request.

\section{Ethics approval and consent to participate}

The use of the CMIS database and biobank for this study was approved by the directors of the CMIS (FK and NL) and the Research Ethics Committee of CHU Sainte-Justine. All participants provided written informed consent.

\section{Consent for publication}

Not applicable.

\section{Competing interests}

IB, HT and FK were the recipients of salary awards (chercheur-boursier) from FRQ-S. HT was the recipient of a New Investigator salary award from the Canadian Institutes of Health Research (CIHR). The authors declare that they have no competing interests.

\section{Author details}

${ }^{1}$ Department of Obstetrics and Gynecology, Faculty of Medicine, Université de Montréal, Montreal, Canada. ${ }^{2}$ Department of Social and Preventive Medicine, Faculty of Medicine, Université de Montréal, Montreal, Canada. ${ }^{3}$ Centre de recherche du CHU Sainte-Justine, Montreal, Canada. ${ }^{4}$ Centre d'infectiologie Mère-Enfant, CHU Sainte-Justine, Montreal, Canada. ${ }^{5}$ Division of Infectious Diseases, CHU Sainte-Justine, Montreal, Canada. ${ }^{6}$ Department of Pediatrics, Faculty of Medicine, Université de Montréal, Montreal, Canada.

${ }^{7}$ Unité d'immunopathologie virale, Centre de recherche du CHU

Sainte-Justine, Montreal, Canada. ${ }^{8}$ Department of Microbiology, Infectiology \& Immunology, Faculty of Medicine, Université de Montréal, Montreal, Canada. ${ }^{9}$ Department of Obstetrics and Gynecology, Centre hospitalier universitaire (CHU) Sainte-Justine, 3175 Côte Sainte-Catherine, Montreal, QC H3T 1C5, Canada.

Received: 31 July 2019 Accepted: 14 November 2019

Published online: 09 December 2019

\section{References}

1. UNAIDS. Fact sheet - Latest global and regional statistics on the status of the AIDS epidemic. 2017 Available from: http://www.unaids.org/en/ resources/documents/2017/UNAIDS FactSheet.

2. Loutfy M, Kennedy VL, Poliquin V, Dzineku F, Dean NL, Margolese S, et al. No. 354-Canadian HIV pregnancy planning guidelines. J Obstet Gynaecol Can. 2018;40(1):94-114.

3. Siegfried $N$, van der Merwe $L$, Brocklehurst $P$, Sint $\Pi$. Antiretrovirals for reducing the risk of mother-to-child transmission of HIV infection. Cochrane Database Syst Rev. 2011;(7):CD003510. https://www.ncbi.nlm.nih.gov/ pubmed/21735394.

4. Panel on Antiretroviral Guidelines for Adults and Adolescents. Guidelines for the use of antiretroviral agents in HIV-1-infected adults and adolescents: Department of Health and Human Services; 2019 updated July 10, 2019 Available from: https://aidsinfo.nih.gov/contentfiles/lvguidelines/ adultandadolescentgl.pdf.

5. World Health Organization. Guideline on when to start antiretroviral therapy and on pre-exposure prophylaxis for HIV: World Health Organization; 2015 Available from: https://www.who.int/hiv/pub/guidelines/earlyrelease-arv/en/

6. Lundgren J, Gatell J, Rockstroh J, Furrer H. EACS Guidelines, version 8.22015 Available from: http://www.eacsociety.org/guidelines/guidelines-archive/ archive.html.

7. Waters L, Ahmed N, Angus B, Boffito M, Bower M, Churchill D, et al. BHIVA guidelines for the treatment of HIV-1-positive adults with antiretroviral therapy 2015 (2016 interim update) 2016 Available from: https://www.bhiva. org/file/RVYKzFwyxpgil/treatment-guidelines-2016-interim-update.pdf

8. Burdge DR, Money DM, Forbes JC, Walmsley SL, Smaill FM, Boucher M, et al. Canadian consensus guidelines for the management of pregnant HIVpositive women and their offspring. CMAJ. 2003;168(13):1671-4. 
9. Brocklehurst $P$, French $R$. The association between maternal HIV infection and perinatal outcome: a systematic review of the literature and metaanalysis. BJOG Int J Obstet Gynaecol. 1998;105(8):836-48.

10. Wedi CO, Kirtley S, Hopewell S, Corrigan R, Kennedy SH, Hemelaar J. Perinatal outcomes associated with maternal HIV infection: a systematic review and meta-analysis. Lancet HIV. 2016;3(1):e33-48.

11. Ekouevi DK, Coffie PA, Becquet R, Tonwe-Gold B, Horo A, Thiebaut R, et al. Antiretroviral therapy in pregnant women with advanced HIV disease and pregnancy outcomes in Abidjan. Cote d'Ivoire Aids. 2008;22(14):1815-20.

12. Townsend CL, Cortina-Borja M, Peckham CS, Tookey PA. Antiretroviral therapy and premature delivery in diagnosed HIV-infected women in the United Kingdom and Ireland. Aids. 2007;21(8):1019-26.

13. Newell M-L, Bunders MJ. Safety of antiretroviral drugs in pregnancy and breastfeeding for mother and child. Curr Opin HIV AIDS. 2013;8(5):504-10.

14. Zash $\mathrm{R}$, Jacobson $\mathrm{DL}$, Diseko $\mathrm{M}$, et al. Comparative safety of antiretroviral treatment regimens in pregnancy. JAMA Pediatr. 2017;171(10):e172222.

15. Lopez M, Figueras F, Hernandez S, Lonca M, Garcia R, Palacio M, et al. Association of HIV infection with spontaneous and iatrogenic preterm delivery: effect of HAART. Aids. 2012;26(1):37-43.

16. Li N, Sando MM, Spiegelman D, Hertzmark E, Liu E, Sando D, et al. Antiretroviral therapy in relation to birth outcomes among HIV-infected women: a cohort study. J Infect Dis. 2015;213(7):1057-64.

17. Alemu FM, Yalew AW, Fantahun M, Ashu EE. Antiretroviral therapy and pregnancy outcomes in developing countries: a systematic review. Int J MCH AIDS. 2015;3(1):31-43.

18. Powis KM, Kitch D, Ogwu A, Hughes MD, Lockman S, Leidner J, et al. Increased risk of preterm delivery among HIV-infected women randomized to protease versus nucleoside reverse transcriptase inhibitor-based HAART during pregnancy. J Infect Dis. 2011;204(4):506-14.

19. Mohammadi H, Papp E, Cahill L, Rennie M, Banko N, Pinnaduwage $L$, et al. HIV antiretroviral exposure in pregnancy induces detrimental placenta vascular changes that are rescued by progesterone supplementation. Sci Rep. 2018;8:6552. https://doi.org/10.1038/s41598-018-24680-w. https://www. nature.com/articles/s41598-018-24680-w\#citeas.

20. Pore N, Gupta AK, Cerniglia GJ, Maity A. HIV protease inhibitors decrease VEGF/HIF-1a expression and angiogenesis in Glioblastoma cells. Neoplasia. 2006:8(11):889-95.

21. Sgadari C, Barillari G, Toschi E, Carlei D, Bacigalupo I, Baccarini S, et al. HIV protease inhibitors are potent anti-angiogenic molecules and promote regression of Kaposi sarcoma. Nat Med. 2002;8:225.

22. Lecarpentier $E$, Vieillefosse $S$, Haddad B, Fournier T, Leguy M-C, Guibourdenche J, et al. Le facteur de croissance placentaire (PIGF) et son récepteur soluble (sFlt-1) au cours de la grossesse: physiologie, dosage et intérêt dans la préeclampsie. Ann Biol Clin. 2016;74(3):259-67.

23. Levine RJ, Maynard SE, Qian C, Lim K-H, England LJ, Yu KF, et al. Circulating Angiogenic factors and the risk of preeclampsia. N Engl J Med. 2004;350(7): 672-83.

24. Levine RJ, Lam C, Qian C, Yu KF, Maynard SE, Sachs BP, et al. Soluble Endoglin and other circulating Antiangiogenic factors in preeclampsia. N Engl J Med. 2006;355(10):992-1005.

25. Govender N, Naicker T, Rajakumar A, Moodley J. Soluble fms-like tyrosine kinase-1 and soluble endoglin in HIV-associated preeclampsia. Eur J Obstet Gynecol Reprod Biol. 2013;170(1):100-5.

26. Chaiworapongsa T, Romero R, Korzeniewski SJ, Kusanovic JP, Soto E, Lam J, et al. Maternal plasma concentrations of angiogenic/antiangiogenic factors in the third trimester of pregnancy to identify the patient at risk for stillbirth at or near term and severe late preeclampsia. Am J Obstet Gynecol. 2013; 208(4):287.e1-e15

27. Romero R, Nien JK, Espinoza J, Todem D, Fu W, Chung H, et al. A longitudinal study of angiogenic (placental growth factor) and antiangiogenic (soluble endoglin and soluble vascular endothelial growth factor receptor-1) factors in normal pregnancy and patients destined to develop preeclampsia and deliver a small for gestational age neonate. J Matern Fetal Neonatal Med. 2008;21(1):9-23.

28. Baltajian K, Bajracharya S, Salahuddin S, Berg AH, Geahchan C, Wenger JB, et al. Sequential plasma angiogenic factors levels in women with suspected preeclampsia. Am J Obstet Gynecol. 2016;215(1):89.e1-e10.

29. Holme AM, Roland MCP, Henriksen T, Michelsen TM. In vivo uteroplacental release of placental growth factor and soluble Fms-like tyrosine kinase-1 in normal and preeclamptic pregnancies. Am J Obstet Gynecol. 2016;215(6): 782.e1-9.
30. Taylor RN, Grimwood J, Taylor RS, McMaster MT, Fisher SJ, North RA. Longitudinal serum concentrations of placental growth factor: evidence for abnormal placental angiogenesis in pathologic pregnancies. Am J Obstet Gynecol. 2003;188(1):177-82.

31. Mijal RS, Holzman CB, Rana S, Karumanchi SA, Wang J, Sikorskii A. Midpregnancy levels of angiogenic markers as indicators of pathways to preterm delivery. J Matern Fetal Neonatal Med. 2012;25(7):1135-41.

32. Romero R, Chaiworapongsa T, Erez O, Tarca AL, Gervasi MT, Kusanovic JP, et al. An imbalance between angiogenic and anti-angiogenic factors precedes fetal death in a subset of patients: results of a longitudinal study. J Matern Fetal Neonatal Med. 2010;23(12):1384-99.

33. Andersen LB, Dechend R, Karumanchi SA, Nielsen J, Joergensen JS, Jensen TK, et al. Early pregnancy angiogenic markers and spontaneous abortion: an Odense Child Cohort study. Am J Obstet Gynecol. 2016;215(5):594.e1-e11.

34. Korzeniewski SJ, Romero R, Chaiworapongsa T, Chaemsaithong P, Kim CJ, Kim YM, et al. Maternal plasma angiogenic index-1 (placental growth factor/soluble vascular endothelial growth factor receptor-1) is a biomarker for the burden of placental lesions consistent with uteroplacental underperfusion: a longitudinal case-cohort study. Am J Obstet Gynecol. 2016;214(5):629.e1-e17.

35. Redman CWG, Staff AC. Preeclampsia, biomarkers, syncytiotrophoblast stress, and placental capacity. Am J Obstet Gynecol. 2015;213(4):S9.e1-4.

36. Fisher SJ. Why is placentation abnormal in preeclampsia? Am J Obstet Gynecol. 2015;213(4):S115-S22

37. Conroy AL, McDonald CR, Gamble JL, Olwoch P, Natureeba P, Cohan D, et al. Altered angiogenesis as a common mechanism underlying preterm birth, small for gestational age, and stillbirth in women living with HIV. Am J Obstet Gynecol. 2017;217(6):684.e1-e17.

38. Harris PA, Taylor R, Thielke R, Payne J, Gonzalez N, Conde JG. Research electronic data capture (REDCap)--a metadata-driven methodology and workflow process for providing translational research informatics support. J Biomed Inform. 2009;42(2):377-81.

39. Yang J, Pearl M, DeLorenze GN, Romero R, Dong Z, Jelliffe-Pawlowski $L$, et al. Racial-ethnic differences in midtrimester maternal serum levels of angiogenic and antiangiogenic factors. Am J Obstet Gynecol. 2016;215(3):359.e1-9.

40. Browne JL, Klipstein-Grobusch K, Koster MP, Ramamoorthy D, Antwi E, Belmouden I, et al. Pregnancy associated plasma protein-a and placental growth factor in a sub-Saharan African population: a nested cross-sectional study. PLoS One. 2016;11(8):e0159592.

41. Andersen LB, Jørgensen JS, Herse F, Andersen MS, Christesen HT, Dechend R. The association between angiogenic markers and fetal sex: implications for preeclampsia research. J Reprod Immunol. 2016;117:24-9.

42. Zera CA, Seely EW, Wilkins-Haug LE, Lim K-H, Parry SI, TF ME. The association of body mass index with serum angiogenic markers in normal and abnormal pregnancies. Am J Obstet Gynecol. 2014;211(3):247.e1-7.

43. Mijal RS, Holzman CB, Rana S, Karumanchi SA, Wang J, Sikorskii A. Midpregnancy levels of angiogenic markers in relation to maternal characteristics. Am J Obstet Gynecol. 2011;204(3):244.e1-e12.

44. Kasdaglis T, Aberdeen G, Turan O, Kopelman J, Atlas R, Jenkins C, et al. Placental growth factor in the first trimester: relationship with maternal factors and placental Doppler studies. Ultrasound Obstet Gynecol. 2010;35(3):280-5.

45. Krauss T, Pauer HU, Augustin HG. Prospective analysis of placenta growth factor (PIGF) concentrations in the plasma of women with Normal pregnancy and pregnancies complicated by preeclampsia. Hypertens Pregnancy. 2004;23(1):101-11.

46. Portelli M, Baron B. Clinical presentation of preeclampsia and the diagnostic value of proteins and their methylation products as biomarkers in pregnant women with preeclampsia and their newborns. J Pregnancy. 2018;2018:2632637.

47. Saffer C, Olson G, Boggess KA, Beyerlein R, Eubank C, Sibai BM. Determination of placental growth factor (PIGF) levels in healthy pregnant women without signs or symptoms of preeclampsia. Pregnancy Hypertens. 2013;3(2):124-32.

48. Tsiakkas A, Duvdevani N, Wright A, Wright D, Nicolaides K. Gynecology. Serum placental growth factor in the three trimesters of pregnancy: effects of maternal characteristics and medical history. J Ultrasound in Obstetrics. 2015;45(5):591-8.

49. Vatten $L$ J, Eskild A, Nilsen TI, Jeansson S, Jenum PA, Staff AC. Changes in circulating level of angiogenic factors from the first to second trimester as predictors of preeclampsia. Am J Obstet Gynecol. 2007;196(3):239. e1-6.

50. Papp E, Mohammadi H, Serghides L. Changes in placental vasculature and pregnancy outcomes in HIV-antiretroviral drug exposed mice. Placenta. 2014;35(9):A17. 
51. Govender N, Naicker T, Moodley J. Maternal imbalance between proangiogenic and anti-angiogenic factors in HIV-infected women with preeclampsia: cardiovascular topics. Cardiovasc J Africa. 2013;24(5):174-9.

52. Powis KM, McElrath TF, Hughes MD, Ogwu A, Souda S, Datwyler SA, et al. High viral load and elevated angiogenic markers associated with increased risk of preeclampsia among women initiating highly active antiretroviral therapy (HAART) in pregnancy in the Mma Bana study, Botswana. J Acquir Immune Defic Syndr. 2013;62(5):517.

53. Wimalasundera R, Larbalestier N, Smith J, De Ruiter A, Thom SM, Hughes A, et al. Pre-eclampsia, antiretroviral therapy, and immune reconstitution. Lancet. 2002:360(9340):1152-4.

\section{Publisher's Note}

Springer Nature remains neutral with regard to jurisdictional claims in published maps and institutional affiliations.

Ready to submit your research? Choose BMC and benefit from:

- fast, convenient online submission

- thorough peer review by experienced researchers in your field

- rapid publication on acceptance

- support for research data, including large and complex data types

- gold Open Access which fosters wider collaboration and increased citations

- maximum visibility for your research: over $100 \mathrm{M}$ website views per year

At $\mathrm{BMC}$, research is always in progress.

Learn more biomedcentral.com/submissions 